\title{
Female Breast
}

National Cancer Institute

\section{Source}

National Cancer Institute. Female Breast. NCI Thesaurus. Code C12851.

The organ of milk secretion; one of two hemispheric projections of variable size situated in the subcutaneous layer over the pectoralis major muscle on either side of the chest of the mature female; it is rudimentary in the male. 